\title{
A NEW SYNTHETIC THIO-CHALCONE INTENDED AS A LIGAND FOR POLYMETALLIC COORDINATION COMPOUNDS: STRUCTURAL, ELECTROCHEMICAL AND THEORETICAL STUDY
}

\author{
F. BROVELLI ${ }^{a}$, R. BAGGIO ${ }^{b}, L_{.}$ÁLVAREZ ${ }^{c}$ AND Y. MORENO ${ }^{d^{*}}$ \\ ${ }^{a}$ Universidad de Concepción, Escuela de Educación, Departamento Ciencias Básicas, Campus Los Angeles, Av. J.A. Coloma 0201, Los Angeles-BioBio, Chile. \\ ${ }^{b}$ Comisión Nacional de Energía Atómica, Gerencia de Investigación y Aplicaciones, Centro Atómico Constituyentes, Buenos Aires, Argentina. \\ ${ }^{\circ}$ Departamento de Química, Universidad Técnica Federico Santa María, Valparaiso, Chile. \\ ${ }^{d}$ Facultad de Ciencias Básicas, Universidad Santo Tomás, Limonares 190, Viña del Mar, Chile.
}

\begin{abstract}
The new chalcone, 1-(PYRIDIN-2-YL)-3-(THIOPHEN-2-YL)PROPENONE, has been synthesized and its crystal and molecular structure determined. An electrochemical characterization of the molecule disclosed some reversible and irreversible processes in its cathodic/anodic reactions. A density functional study was carried out in order to calculate the frontier molecular orbitals and the diffusion coefficient, which showed very good agreement with the experimental data.
\end{abstract}

Keywords: Chalcone, cyclic voltammetry, DFT calculations, crystal structure, diffusion coefficient.

\section{INTRODUCTION}

Chalcones are $\alpha, \beta$-unsaturated carbonyl compounds constituting a particular subclass of flavonoids [1] with a high therapeutic and preventive potential for many diseases, showing antibacterial, antifungal, antitumor and antiinflammatory properties [2-7]. In addition, chalcones derivatives have also been employed as electroactive materials in organic light emitting diodes (OLED) [811], non-linear optical (NLO) [12-17], and fluorescent [18] materials.

This work is part of a research line propelled by our interest on ligands that may lead to polymetallic coordination compounds. In this regard, an $\alpha, \beta$ unsaturated carbonyl system can be attacked by a nucleophilic species, resulting in a compound with different electron-donating atoms, i.e., a ligand with greater tendency to coordinate specific ions. On the other hand, these unsaturated carbonyl compounds attached to aromatic rings may result in conjugated systems, and could thus be promising candidates to be invested with interesting physicochemical properties. These characteristics have led us to choose electrochemical techniques in order to investigate the electronic nature of the investigated ligands [19-24].

In this report we include a thorough study (synthesis, crystal and molecular structure and electrochemical characterization) of 1-(pyridin-2-yl)-3-(thiophen2-yl) propenone, $\mathrm{C}_{12} \mathrm{H}_{9} \mathrm{OSN}$, (hereinafter PyCHL, Scheme 1).

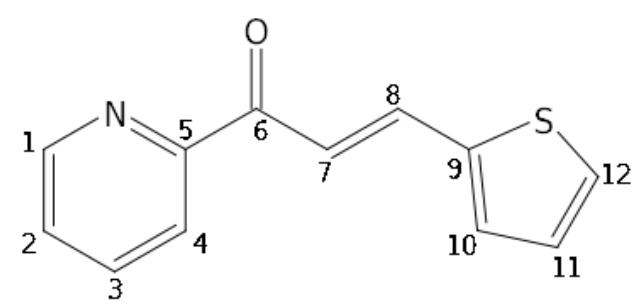

Scheme 1: Molecular diagram for PyCHL.

A density functional theory (DFT) study has also been carried out in order to calculate diffusion coefficient and molecular orbitals.

\section{EXPERIMENTAL}

\section{Synthesis and characterization.}

Compound $\boldsymbol{P y} \boldsymbol{C H L}$ was synthesized according to literature [25,26]. $0.285 \mathrm{~g}$ $(2,35 \mathrm{mmol})$ of 2-acetylpyridine were dissolved in a $10 \% \mathrm{KOH}$ solution in 1:1 ethanol/water, then $0.220 \mathrm{~g}(1.97 \mathrm{mmol})$ of 2-thiophenecarboxaldehyde were added and the solution left overnight at room temperature. This was further neutralized with a few drops of $\mathrm{HCl} 1 \mathrm{M}$ and the precipitated was filtered and washed with plenty of water. A yellow solid was obtained with a $47 \%$ of yield. The product was recrystallized from hot ethanol.

The FT-IR spectrum was recorded on a Shimadzu, IR-Prestige-21, using $\mathrm{KBr}$ pellets and the following bands were found: $1660(v \mathrm{C}=\mathrm{O}) ; 1573(\vee(\mathrm{C}=\mathrm{C}, \mathrm{C}=\mathrm{N})$ pyridine ring $) ; 1312,1283(\delta \mathrm{CH}$ thiophene ring $) ; 994$ (= $\left.\mathrm{CH} \delta_{\text {oop trans }}\right) ; 872,840$ $\left(\delta \mathrm{CH}_{\text {oopthiophene ring sust-2 }}\right) ; 792,739,704\left(\delta \mathrm{CH}_{\text {ooppryridine ring sust-2 }}\right) \mathrm{cm}^{-1}[8]$.

${ }^{1} \mathrm{H}-\mathrm{NMR}$ was recorded on an AVANCE 400 Digital Bruker NMR spectrometer (chemical shifts references to residual solvent peaks, TMS $=0$ ) using $\mathrm{CDCl}_{3}$ as solvent. The chemical shifts recorded can be assigned to ${ }^{1} \mathrm{H}-$ RMN $\left(\mathrm{CDCl}_{3}\right): 7.0936(\mathrm{dd}, J=5.0,3.7 \mathrm{~Hz}, 1 \mathrm{H}, \mathrm{H}-11) ; 7.4188(\mathrm{~d}, J=3.6 \mathrm{~Hz}$, $1 \mathrm{H}, \mathrm{H}-10) ; 7.4395$ (d, $J=5.0 \mathrm{~Hz}, 1 \mathrm{H}, \mathrm{H}-12) ; 7.4870$ (ddd, $J=7.4,4.8,0.9 \mathrm{~Hz}$, $1 \mathrm{H}, \mathrm{H}-2) ; 7.8729$ (ddd, $J=7.7,7.7,1.6 \mathrm{~Hz}, 1 \mathrm{H}, \mathrm{H}-3$ ); 8.0665 (s, 2H, H-7, H-8); $8.1752(\mathrm{~d}, J=7.9 \mathrm{~Hz}, 1 \mathrm{H}, \mathrm{H}-4) ; 8.7474(\mathrm{~d}, J=4.5 \mathrm{~Hz}, 1 \mathrm{H}, \mathrm{H}-1)$ and they are in agreement with what reported in the literature [27].

\section{Electrochemical setup.}

Experimental setup to perform cyclic voltammetry (CV) have been described elsewhere $[25,26]$. In this study, the electrochemical experiments were performed in a Wavenow USB potentiostat/galvanostat (PINE research instruments, USA): a glassy carbon electrode (GCE) (Bioanalytical System Inc, BASi) of $0,07 \mathrm{~cm}^{2}$ geometric area was used as working electrode. The reference electrode was $\mathrm{Ag} / \mathrm{AgCl}$ in a tetraethylammonium chloride solution and its potential was adjusted with respect to the saturated calomel electrode (SCE) [28].

As auxiliary electrode a platinum coil was used, in a separated compartment from the working electrode. To avoid the gradual deactivation of GCE during its use, the procedure described by Kuwana et al. $[29,30]$ was followed to activate it again. The GCE was rinsed with abundant deionized water and then with anhydrous acetonitrile.

Anhydrous acetonitrile (Aldrich Chemical Co) was used as solvent and it was manipulated with a syringe. The supporting electrolyte tetrabutylammonium tetrafluoroborate, $\left(\mathrm{TBABF}_{4}\right)($ Aldrich Chemical $\mathrm{Co})$ was dried under vacuum at $40^{\circ} \mathrm{C}$ for $24 \mathrm{~h}$.

The solution was gasified with Argon during 15 min after each experiment, and kept under an inert atmosphere during electrochemical perturbation.

\section{X-ray diffraction.}

Single crystal diffraction patterns were recorded with a Bruker SMART AXS CCD diffractometer with graphite-monochromated Mo Ka radiation $(\lambda=0.71073 \AA)$ and a semi-empirical absorption correction based on symmetry equivalent reflections was applied. A total of 17076 reflections were collected, providing a unique data set of 2865 reflections $\left(R_{i n t}=0.055\right)$ of which 2368 had I $>$ 2(I). The structure was solved by direct methods with SHELXS [31] and refined by the full-matrix least-squares based on $\mathrm{F}^{2}$ using SHELXL-2014 [32]. Structure analysis was performed with the aid of the PLATON software [33]. Figures were produced with XP in the SHELXTL crystallographic package [31].

Crystallographic data for $\boldsymbol{P y} \boldsymbol{C H L}$ has been deposited at the CCDC under code CCDC2003362. These data can be obtained free of charge via the CCDC retrieval website http://www.ccdc.cam.ac.uk/conts/retrieving.html. 


\section{Computing calculations.}

DFT calculations were performed with the Gaussian 09 suite of programs [34]. The geometry of the molecule was optimized without symmetry restrictions at B3LYP/6-311+G(d,p) level theory. The diffusion coefficient was calculated theoretically from the Stoke-Einstein approach $[35,36]$.

$$
D=\frac{K_{B} T}{6 \pi \eta r}
$$

Where $K_{B}$ is the Boltzmann constant, T the temperature (298 K), $\eta$ the viscosity of the solvent, in this case acetonitrile $\left(3.5 \times 10^{-4} \mathrm{Pas}\right)$ and $\mathrm{r}$ is the radius of solute. The value of the radius was obtained using the keyword volume $=$ tight in the geometrical optimization. The geometrical optimization was performed at M052X/6-31G+(d,p) level theory in acetonitrile solution using a SMD continuum model [37].

\section{RESULTS}

\section{Crystal structure analysis}

Table 1. Experimental details for $\boldsymbol{P y C H L}$.

Crystal data

\begin{tabular}{|l|l|}
\hline Chemical formula & $\mathrm{C}_{12} \mathrm{H}_{9} \mathrm{NOS}$ \\
\hline $\mathrm{Mr}$ & 215.26 \\
\hline Crystal system, space group & Monoclinic, C2/c \\
\hline Temperature $(\mathrm{K})$ & 296 \\
\hline$a, b, c(\AA)$ & $25.085(3), 6.2213(7), 15.1975(18)$ \\
\hline$\beta\left({ }^{\circ}\right)$ & $118.851(4)$ \\
\hline$V\left(\AA^{3}\right)$ & $2077.4(4)$ \\
\hline$Z, Z^{\prime}$ & 8,1 \\
\hline Radiation type & Mo K $\alpha$ \\
\hline$\mu\left(\mathrm{mm}^{-1}\right)$ & 0.28 \\
\hline
\end{tabular}

\section{Data collection}

\begin{tabular}{|l|l|}
\hline Diffractometer & Bruker SMART AXS CCD \\
\hline Absorption correction & Semi-empirical \\
\hline $\begin{array}{l}\text { No. of measured, independent and } \\
\text { observed }[\mathrm{I}>2 \sigma(\mathrm{I})] \text { reflections }\end{array}$ & $17076,2865,2368$ \\
\hline Rint & 0.055 \\
\hline$(\sin \theta / \lambda) \max \left(\AA^{-1}\right)$ & 0.705 \\
\hline
\end{tabular}

\section{Refinement}

\begin{tabular}{|l|l|}
\hline$R\left[\mathrm{~F}^{2}>2 \sigma\left(\mathrm{F}^{2}\right)\right], w R\left(\mathrm{~F}^{2}\right), S$ & $0.046,0.120,1.04$ \\
\hline No. of reflections & 2865 \\
\hline No. of parameters & 149 \\
\hline No. of restraints & 12 \\
\hline $\mathrm{H}$-atom treatment & $\mathrm{H}$-atom parameters constrained \\
\hline$\Delta \rho_{\max }, \Delta \rho_{\min }\left(\mathrm{e} \AA^{-3}\right)$ & $0.49,-0.28$ \\
\hline
\end{tabular}

Table 1 presents some data collection and refinement parameters for $\boldsymbol{P y} \boldsymbol{C H L}$, while in Figure 1 an ellipsoid plot of the molecule, drawn at a 50\% probability level, is provided. The compound crystallizes in the monoclinic space group $\mathrm{C} 2 / \mathrm{c}$ $(Z=8)$ with one single molecule in the asymmetric unit $\left(Z^{\prime}=1\right)$.

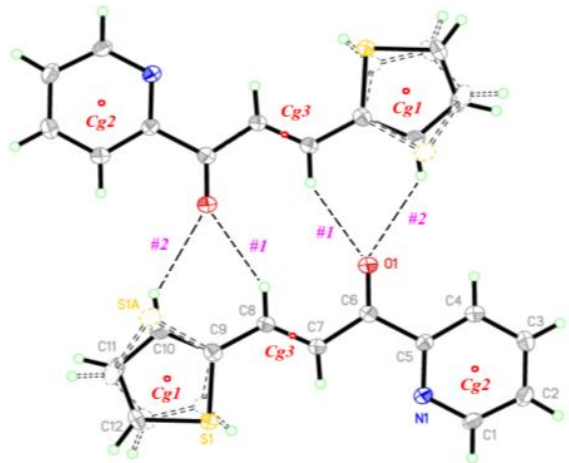

Figure 1. The dimeric unit built up by interactions \#1 and \#2. Displacement ellipsoids in both moieties drawn at a $50 \%$ probability level. The one below shows the labeling scheme used, both for atoms as for centroids.
The molecule is made up of three planar entities, viz., a propenone core, acting as a bridge between two terminal aromatic groups, a pyridyl and a thiophene rings, this latter one appearing slightly disordered via a $180^{\circ}$ rotation around the C7-C8 bond (population of the major fraction, 92\%). The whole entity is basically planar, though with small deviations due to out-of-plane rotations of the terminal rings, as assessed by some torsion angles significantly different from 0, $180^{\circ}$ (N1 C5 C6 C7 9.7(2) ${ }^{\circ}$ C4 C5 C6 C7 -170.93(16) ${ }^{\circ}$; C7 C8 C9A C10A 9.1(13) $)^{\circ}$; C7 C8 C9A S1A $\left.173.9(5)^{\circ}\right)$.

The most interesting structural aspect is the spatial disposition of the molecules, and the well differentiated role which each one of the non-covalent interactions play in its building up. The most relevant ones are presented in Table 2 , with the addition of an interaction code (\#n) intended for easy of reference in the figures.

Table 2. Non-covalent interactions in $\mathrm{PyCHL}$

H-bonding interactions

\begin{tabular}{|c|c|c|c|c|c|}
\hline Code & $\mathbf{D}-\mathbf{H} \cdots \mathbf{A}$ & D-H( $(\AA)$ & $\mathbf{H} \cdots \mathbf{A}(\AA)$ & $\mathbf{D} \cdots \mathbf{A}(\AA)$ & D- $-H^{\prime} \cdots A\left({ }^{\circ}\right)$ \\
\hline$\# 1$ & C8--H8...O $1^{\mathrm{i}}$ & 0.93 & 2.47 & $3.302(2)$ & 148 \\
\hline$\# 2$ & $\mathrm{C} 10-\mathrm{H} 10 \ldots \mathrm{O} 1^{\mathrm{i}}$ & 0.93 & 2.55 & $3.328(3)$ & 142 \\
\hline \#3 & $\mathrm{C} 2-\mathrm{H} 2 \ldots \mathrm{Cg} 1^{i \mathrm{ii}}$ & 0.93 & 2.63 & 3.414 & 142 \\
\hline
\end{tabular}

\section{$\pi \pi$ contacts}

\begin{tabular}{|c|cc|c|c|}
\hline Code & $\mathbf{C g} . . . \mathbf{C g}$ & $\mathbf{d}(\boldsymbol{\pi}$ & $\boldsymbol{\pi}) \mathbf{(} \boldsymbol{\AA})$ & $\mathbf{C g 2 - C g 3 p e r p}\left({ }^{\circ}\right)$ \\
\hline$\# 4$ & $\mathrm{Cg} 2$ & $\mathrm{Cg} 3 \mathrm{iii}$ & $3.592(3)$ & $15.4(3)^{\circ}$ \\
\hline
\end{tabular}

Anion...Anion contacts
\begin{tabular}{|c|c|c|}
\hline Code & An...An & d(An...An) $(\mathbf{\AA})$ \\
\hline$\# 5$ & S1...N $1^{\text {iv }}$ & $3.2276(16)$ \\
\hline
\end{tabular}

Symmetry codes: (i), -x, -y, -z, (ii), x, 1-y, -1/2+z; (iii), x, 1+y, z; (iv) 1/2-x, $-1 / 2+\mathrm{y}, 1 / 2-\mathrm{z}$.

The 3D structure can be envisaged as constructed in a stepwise fashion, where the elemental building brick is a centrosymmetric dimeric unit due to interactions $\# 1$ and \#2, and shown in Figure 1 .

The slight rotational disorder in the thiophene ring is the cause for interaction \#2 not being active all the time. However, an alternative interaction appears in replacement of $\# 2$, in the form of a short S1A...O $1^{\mathrm{i}}$ contact, 3.112(3) $\dot{A}$ in length, and this may be a reason for the stability of the disordered moiety.

The inversion center giving rise to the dimers lay in the molecular plane, for what the dimeric units are basically planar themselves. They dispose in a slanted fashion to the cell axis, approximately parallel to the (2 12 3) direction, and stack along the short $b$ axis, interacting with each other via a rather unfrequent $\pi \ldots \pi$ bond type (\#3 in Table 2) involving the phenyl aromatic ring and the $\mathrm{C}=\mathrm{C}$ double bond in the propanone unit (Figure2a).

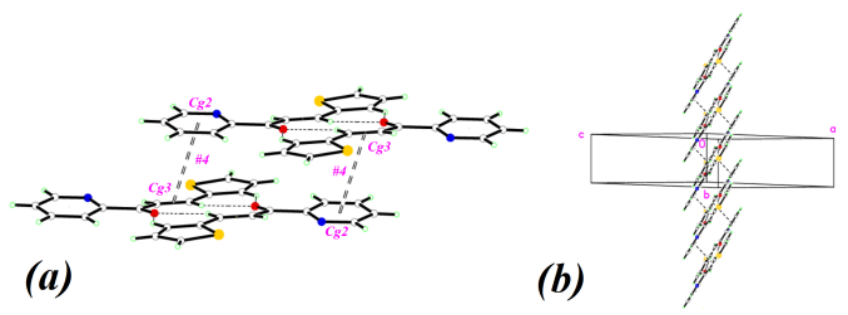

Figure2 (a) The staking along $\boldsymbol{b}$ of two neighbouring dimmers. (b) The [010] column generated. Note the highly slanted orientation of the dimmers.

This staking defines the columns shown in Figure2b. Since the repetition scheme is the [010] translation, all the dimers have the same orientation. Let's call this column type "A".

Since the screw axis in the cell do not go through the columns (they are slightly offset instead) they generate parallel columns to the one described, made up with dimers having their planes at a different orientation, forming an angle of $62^{\circ}$ to their neighbour's (Columns type "B"). The final result is a sequence of columns with alternating dimer orientation (..."A"-"B"-"A"...) juxtaposed along the $\boldsymbol{a}$ - $\boldsymbol{c}$ diagonal, with what a wide (-101) plane builds up, and which can be seen in Figure3 (highlighted). 


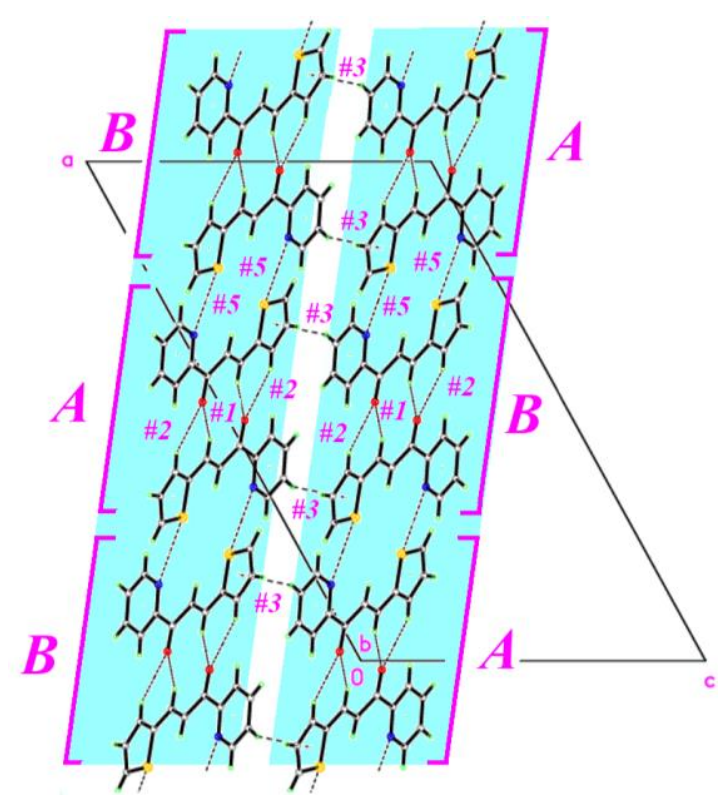

Figure 3.Projection of the structure along the unique axis $\boldsymbol{b}$. The columns shown alongside in Figure $2 \mathrm{~b}$ are now seen in projection, and labeled " $\mathrm{A}$ " and "B", according to the dimers orientation (see text). Note the anion-anion interaction (\#2), defining the (-101) planar

The square brackets pinpoint the different [010] "A" and "B" columns, now seen in projection. The link between columns, basically along the $c$ axis, is the short S...N contact (\#4), 3.2276(16) $\dot{A}$ in length (about $0.12 \dot{A}$ shorter than the sum of the corresponding van der Waals radii, $3.35 \dot{\mathrm{A}}$ ).

The resulting 3D crystal structure is rather compact, as assessed by its largerthan-usual Kitaigorodskii, Packing Index [38] measuring the Percent Filled Space, and which calculated by PLATON[33] amounts 69.8\%. Expected values for organic structures lay in the range $66-68 \%$.

\section{Cyclic Voltammetry.}

The electrochemical behavior of $\boldsymbol{P y C H L}$ is shown in Figure 4.
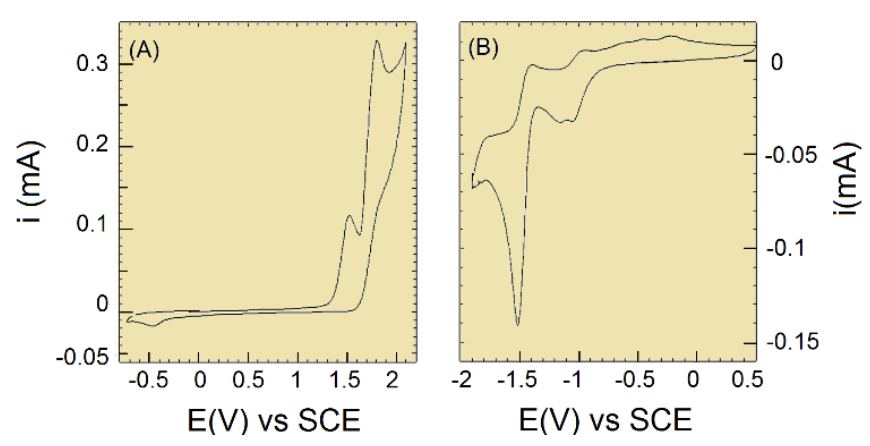

Figure 4. Electrochemical behaviour of $\boldsymbol{P y C H L} 5 \mathrm{mM}$ in anhydrous acetonitrile with tetrabutylammonium tetrafluoroborate at $100 \mathrm{mV} / \mathrm{s}$ on glassy carbon electrode. A) anodic scan and B) cathodic scan.

In the anodic scan (Figure 4A), two successive oxidation peaks are observed at $1,49 \mathrm{~V}$ (I) and 1,76 V (II) vs SCE respectively. Both peaks were irreversible, since in the return sweep no reduction peak was observed until at least $-0,46 \mathrm{~V}$ $v s$ SCE. In this same path, a closer inspection of the cyclic voltammograms reveals that the current at the foot of the anodic wave is independent of the sweep rate. This feature suggest that the electron transfer is totally irreversible [39] and it is similar to those found with other chalcones in aprotic medium $[8,26]$. When successive anodic scans were recorded a significant decrease in the anodic peak current was observed along with a displacement of the oxidation peak towards higher potentials, which may indicate the depletion of neutral molecules of chalcone $[26,40,41]$. The effect of the scan rate on the anodic peak potential and current peak was studied.

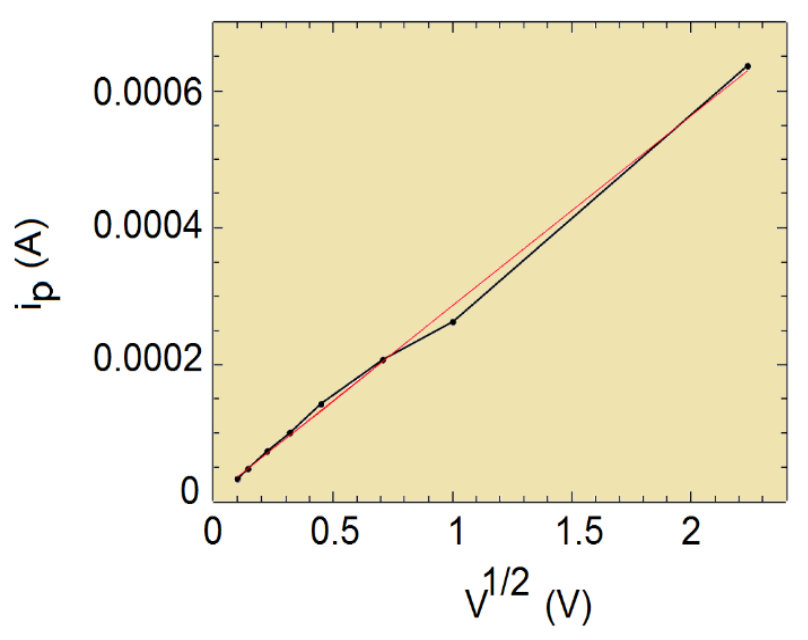

Figure 5. Relation between $\mathrm{i}_{\mathrm{p}} v s \mathrm{v}^{1 / 2}$ for anodic peak (I).

The anodic peak current $\left(\mathrm{i}_{\mathrm{p}}\right)$ was proportional to the square root of the scan rate $\mathrm{v}(\mathrm{R}=0,99)$ (Figure 5), which is consistent with the diffusion as the rate-limiting step [42] in the $\boldsymbol{P y} \boldsymbol{C H} \boldsymbol{L}$ electrochemical oxidation. Likewise, the relationship between $\left(\mathrm{E}_{\mathrm{p}}-\mathrm{E}_{\mathrm{p} / 2}\right)$ is close to $115 \mathrm{mV}$, which is considerably larger than $59 \mathrm{mV}$ expected for a reversible charge-transfer step [42] and it increased with the scan rate, which confirm that the oxidation of $\boldsymbol{P y} \boldsymbol{C H} \boldsymbol{L}$ was irreversible. The relation $\mathrm{E}_{\mathrm{p}} v s \ln \mathrm{v}[40,42]$ yields a linear relationship with a slope of $0.0476(\mathrm{R}=0.98)$ with which a value of $\beta \mathrm{n}_{\mathrm{b}}$ of 0.62 is obtained; a similar relation was found between $\mathrm{E}_{\mathrm{p}} v s \ln \mathrm{i}_{\mathrm{p}}[42,43]$, whose slope is $0.0983(\mathrm{R}=0.99)$ obtaining a value of $\beta n_{b}$ of 0.60 , which confirms the irreversible behavior of $\boldsymbol{P y} \boldsymbol{C H L}$ oxidation. From the relation $\mathrm{i}_{\mathrm{p}} v s \mathrm{v}^{1 / 2}$ a value for $D_{0}$ of $1,4 \times 10^{-6}(\mathrm{~cm} / \mathrm{s})$ was obtained $[44,45]$.

In the case of cathodic behavior (Figure 4B), three reduction peaks are observed at -1.05 and $-1.16 \mathrm{~V}$ and a well defined peak reduction at $-1.52 \mathrm{~V} v s$ SCE. In the return scan, an oxidation peak is observed at $-0.93 \mathrm{~V}$ vs SCE, which is related to the reduction peak at $-1,161 \mathrm{~V}$ vs SCE. However, the reduction observed at $-1,53 \mathrm{~V}$ was irreversible $[8,26]$ and it can be attributed to carbonyl group reduction $[8,46-48]$. This reduction has shown a mixed adsorptive and diffusive response [49]. The cathodic peak observed at -1,58 V vs SCE with $\mid \mathrm{E}_{\mathrm{p}}-$ $\mathrm{E}_{\mathrm{p} / 2} \mid=65 \mathrm{mV}$ reflects $1 \mathrm{e}^{-}$transfer.

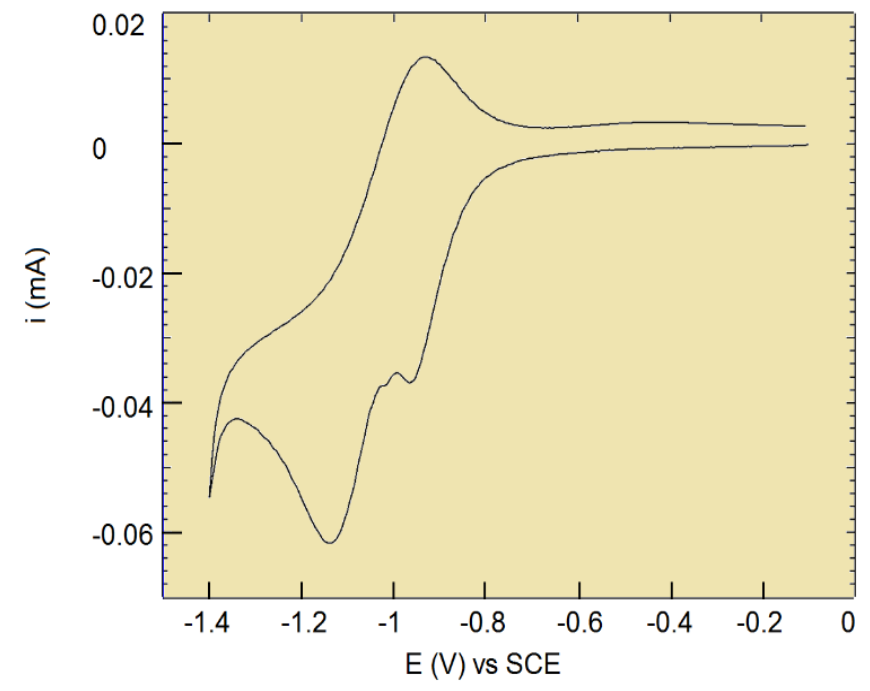

Figure 6. Cathodic voltammogram of $\boldsymbol{P y} \boldsymbol{C H L}(0,005 \mathrm{M})$ with tetrabutylammonium tetrafluoroborate $0,1 \mathrm{M}$ in anhydrous acetonitrile on glassy carbon electrode. Scan rate $100 \mathrm{mV} / \mathrm{s}$.

A closer inspection of the reduction peaks found at $-0.93 \mathrm{~V}$ and $-1.161 \mathrm{~V}$ (Figure 6) reveals the presence of a quasi reversible system, which has been described for pyridine derivatives, in which a species of the dihydropyridine type is involved (Scheme 2). 


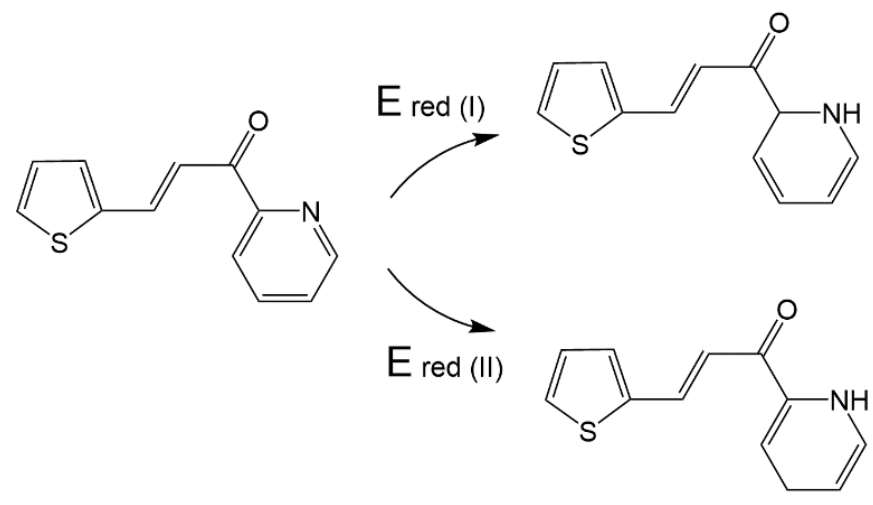

Scheme 2: Possible products from cathodic reduction of $\boldsymbol{P y C H L}$ peak (I) and (II) respectively.

\section{Computational calculations.}

\section{Diffusion coefficient.}

The diffusion coefficient $\left(D_{0}\right)$ of $\boldsymbol{P y} \boldsymbol{C H} \boldsymbol{L}$ was evaluated from the slope of the relation $\mathrm{I}_{\mathrm{p}} \mathrm{vs} v^{1 / 2}$ for an irreversible transfer charge described by GonzalezVelasco [45]. This value can be calculated also theoretically from the StokeEisntein approach $[36,37]$. The value of the calculated diffusion coefficient was $1,28 \times 10^{-6}(\mathrm{~cm} / \mathrm{s})$ and it is very close to the one obtained by electrochemical measurements $\left(1,4 \times 10^{-6} \mathrm{~cm} / \mathrm{s}\right)$.

The electronic behavior of $\boldsymbol{P y C H L}$ can be visualized from its molecular orbitals. The chalcones of this study have two hetero-aromatic rings (thiophene and pyridine) that are linked by an $\alpha, \beta$-unsaturated carbonyl system. The HOMO orbital is localized in the thiophene linked vinyl scaffold, and this ring undergoes the first oxidation step according to previous results [26] (Figure 7). This fact explains the existence of two anodic peaks during cyclic voltammetry.

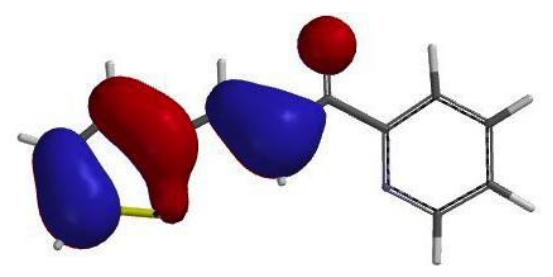

HOMO

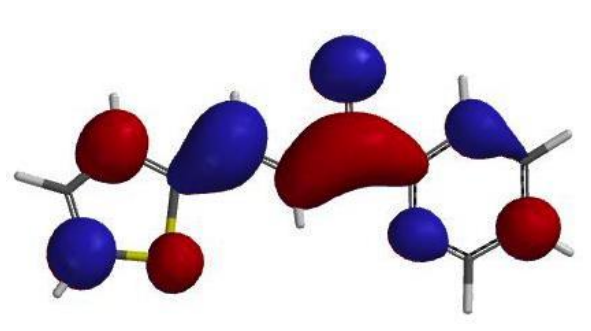

LUMO

Figure 7. Frontier molecular HOMO and LUMO orbitals of PyCHL.

The LUMO orbital is distributed throughout the molecule, so the electrochemical reduction of this compound would allow a better delocalization of the electronic charge. In addition, the contribution of the pyridine ring in the LUMO orbital explains the presence of two reduction peaks, which can be attributed to the reduction to a dihydropyridine system, before the reduction of the carbonyl group.

Summarizing the preceding analysis: the electrochemical behavior of $\boldsymbol{P y C H L}$ shows two oxidations peaks and both are irreversible, while the electrochemical reduction shows three processes: the first two peaks, attributable to the reduction of the pyridine ring to dihydropyridine, and the third one, to the reduction of the carbonyl group.

\section{CONCLUSIONS}

Compound $\boldsymbol{P y} \boldsymbol{C H L}$ has an almost flat molecular structure, in which two units associate to give rise to a centrosymmetric system whose stability comes from a variety of non-covalent interactions.

The electrochemical behavior of $\boldsymbol{P y} \boldsymbol{C H L}$ shows two oxidations peaks and both are irreversible, while the electrochemical reduction shows three process, the first two peaks could be attributed to the reduction of the pyridine ring to dihydropyridine and the third peak to the reduction of the carbonyl group. From the relation $\mathrm{i}_{\mathrm{p}} v s \mathrm{v}^{1 / 2}$ a value for $\mathrm{D}_{0}$ of $1,4 \times 10^{-6}(\mathrm{~cm} / \mathrm{s})$ was obtained, which is in agreement with the value calculated theoretically.

The FMO indicates that the HOMO orbital is located in the vinyl sector attached to the thiophene while the LUMO orbital is distributed throughout the molecule.

\section{ACKNOWLEDGEMENTS}

The authors acknowledge financial support from UDECVRID 216.412.0491.0 .

\section{REFERENCES}

1. C.B. Patil, S.K. Mahajan, S.A. Katti, J. Pharm. Sci. \& Res.1 (2009) 11-22.

2. R.G. Damazio, A.P. Zanatta, L.H. Cazarolli, L.D. Chiaradia, A. Mascarello, R.J. Nunes, R.A. Yunes, F.R.M. Barreto Silva, Eur. J. Med. Chem. 45 (2010) 1332-1337.

3. K. Juvale, V.F.S. Pape, M. Wiese, Bioorg. Med. Chem. 20 (2012) 346-355.

4. P. Champelovier, M. Mininno, E. Duchamp, E. Nicolle, V. Curri, A. Boumendjel, J. Boutonnat, Anticancer Res. 31 (2011) 3213-3218.

5. J. Wu, J. Li, Y. Cai, Y. Pan, F. Ye, Y. Zhang, Y. Zhao, S. Yang, X. Li, G. Liang, J. Med. Chem. 54 (2011) 8110-8123.

6. A.M. Katsori, D. Hadjipavlou-Litina, Expert Opin.Ther. Pat. 21 (2011) 1575-1596.

7. D. Kamalakkannan, G. Vanangamudi, R. Arulkumaran, K. Thirumurthy, P. Mayavel, G. Thirunarayanan, Elixir Org. Chem. 46 (2012) 8157-8166.

8. F. Brovelli, B. L. Rivas, L. Basaez, J. Chil. Chem. Soc. 48 (4) (2003) 143140.

9. F. Brovelli, J. C. Bernède, S. Marsillac, F. R. Díaz, M. A. Del Valle, C. Beaudouin, J. Appl. Polym. Sci. 86 (2002) 1128-1137.

10. F. Brovelli, F. R. Díaz, M. A. del Valle, J. C. Bernede, P. Molinie, Synth. Met. 122 (2001) 123-126

11. R. Sens, K.H. Drexhage, Journal of Luminiscence, 24-25 (1981) 709-712.

12. Y. Kawabe, H. Ikeda, T. Sakai, K. Kawasaki. J. Mater. Chem. 2 (1992) 1025-1031.

13. B. T. Thaker, D. B. Solanki, B. S. Patel, N. B. Patel, Liquid Crystals 40 (2013) 1296-1309.

14. C. V. Yelamaggad, N. L. Bonde, A. S. Achalkumar, D. S. S. Rao, S. K. Prasad, A. K. Prajapati. Chem. Mater. 19 (2007) 2463-2472.

15. M. Guo, X. Wang, Eur. Polym. J. 45 (2009) 888-898.

16. H. N. Chauhan, A. V. Doshi, Molecular Crystals and Liquid Crystals 570 (2013) 92-100.

17. V. S. Pandey, R. Dhar, A. K. Singh, A. S. Achalkumar, C. V. Yelamaggad, Phase Transitions 83 (2010) 1049-1058.

18. B. Delavaux-Nicot, S. Fery-Forgues, Eur. J. Inorg. Chem. (1999) 18211825.

19. B. Uslu, S. A. Ozkan, Anal. Chim.Acta, 462 (2002) 49-57.

20. T. B. Demircigil, S. A. Ozkan, O. Coruh, S. Yilmaz, Electroanalysis, 14 (2002) 122-127.

21. P. Zuman, "Substituent Effects in Organic Polarography", Plenum Press, NewYork. (1967) 43-130.

22. D. W. Boykin, M. L. Ash, F. L. O. Berin,J. Org. Chem. 37 (1972) 106-110.

23. J. A. Alston, A. J. Fry, Electrochim. Acta 49 (2004)455-459.

24. D. Moraleda, D. E. Abed, H. Pellissier, M. Santelli, J. Mol. Struct. (THEOCHEM) 760 (2006) 113-119.

25. F. Brovelli, M.A. del Valle, F.R. Díaz, J.C. Bernède, Bol. Soc. Chil. Quim. 46 (2001) 319-337.

26. R. Baggio, F. Brovelli, Y. Moreno, M. Pinto, J. Soto-Delgado, Journal of Molecular Structure 1123, (2016)1-7

27. K. Shibata, I. Katsuyama, M. Matsui, H. Muramatsu, J. Heterocyclic. Chem., 28, (1991) 161-165.

28. G. East, M. A. del Valle, J. Chem. Educ. 77 (1) (2000) 97.

29. I. F. Hu, D. H. Karweik, T. Kuwana, J. Electroanal. Chem., 188(1) (1985) $59-72$

30. G. W. Hance, T. Kuwana, Anal. Chem, 59 (1) (1987) 131-134. 
31. G.M. Sheldrick, ActaCrystallogr. Sect. A, 64 (2008) 112-122.

32. G.M. Sheldrick, ActaCrystallogr. Sect. C, 71 (2015) 3-8.

33. A.L. Spek, ActaCrystallogr. Sect. D, 65 (2009) 148-155.

34. Gaussian 09, Revision A.01, M. J. Frisch, G. W. Trucks, H. B. Schlegel, G. E. Scuseria, M. A. Robb, J. R. Cheeseman, G. Scalmani, V. Barone, B. Mennucci, G. A. Petersson, H. Nakatsuji, M. Caricato, X. Li, H. P. Hratchian, A. F. Izmaylov, J. Bloino, G. Zheng, J. L. Sonnenberg, M. Hada, M. Ehara, K. Toyota, R. Fukuda, J. Hasegawa, M. Ishida, T. Nakajima, Y. Honda, O. Kitao, H. Nakai, T. Vreven, J. A. Montgomery, Jr., J. E. Peralta, F. Ogliaro, M. Bearpark, J. J. Heyd, E. Brothers, K. N. Kudin, V. N. Staroverov, R. Kobayashi, J. Normand, K. Raghavachari, A. Rendell, J. C. Burant, S. S. Iyengar, J. Tomasi, M. Cossi, N. Rega, J. M. Millam, M. Klene, J. E. Knox, J. B. Cross, V. Bakken, C. Adamo, J. Jaramillo, R. Gomperts, R. E. Stratmann, O. Yazyev, A. J. Austin, R. Cammi, C. Pomelli, J. W. Ochterski, R. L. Martin, K. Morokuma, V. G. Zakrzewski, G. A. Voth, P Salvador, J. J. Dannenberg, S. Dapprich, A. D. Daniels, Ö. Farkas, J. B. Foresman, J. V. Ortiz, J. Cioslowski, and D. J. Fox, Gaussian, Inc., Wallingford CT (2009).

35. A. Einstein, Ann. Phys. (Leipzig) 17 (1905) 549-560

36. G.G. Stoke, Mathematical and Physical Papers, Vol. 3. Cambridge University Press, Cambridge, (1903) (esp. Sect. IV).
37. A.V. Marenich, C.J. Cramer, D.G. Truhlar. J. Phys. Chem. B 113 (2009) 6378-6396.

38. A. I. Kitaigorodskii, In Organic Chemical Crystallography (1961) New York: Consultants Bureau.

39. W. H. Reinmuth, Anal. Chem., 32 (1960) 1891-1892

40. P. Delahey, J. Am. Chem. Soc., 75 (1953) 1190-1196

41. Keerti M. Naik, Sharanappa T. Nandibewoor, American Journal of Analytical Chemistry, 3 (2012) 656-633.

42. R. S. Nicholson, I. Shain, Anal. Chem., 36(4) (1964) 706-723

43. A. Y. Gokhshtein, V. P. Gokhshtein, Dokl.Akad.NaukSSSR131 (1960) 601

44. R. J. Kingler, J. K. Kochi, J. Am Chem. Soc., 102(14) (1980) 4790-4798

45. J. González-Velasco, Electroanalysis 6(9) (1994) 711-724

46. M. Dhananjayulu, M. SivaPrasad, Ch. Swarupa, M. Seenu Naik, N.Y. Sreedhar, International Journal of Innovative Research in Science, Engineering and Technology, 3(5) (2014) 12496-12501.

47. S. Wawzonek, A. Gundersen, Journal of Electrochemical Society111(3) (1964) 324-328.

48. J. P Zimmer, J. A. Richards, J. C. Turner, D. H. Evans, Analytical Chemistry, 43 (8) (1971) 1000-1006.

49. E.M. Tavares, A. M. Carvalho, L. M. Goncalves, I. M. Valente, M. M. Moreira,L.F. Guido, J. A. Rodrigues, T. Doneux, A. A. Barros, Electrochim. Acta 90(15) (2013) 440-444. 